\title{
Effect of magnesium acetylacetonate on the signal of organic forms of vanadium in graphite furnace atomic absorption spectrometry
}

\author{
Zofia Kowalewska ${ }^{\mathrm{a}, *}$, Bernhard Welz ${ }^{\mathrm{b}, \mathrm{c}}$, Ivan N.B. Castilho ${ }^{\mathrm{b}}$, Eduardo Carasek ${ }^{\mathrm{b}}$ \\ ${ }^{a}$ Research-Development Center for Refinery Industry S.A., Chemików 5, 09-411 Płock, Poland \\ ${ }^{\mathrm{b}}$ Departamento de Química, Universidade Federal de Santa Catarina, 88040-900 Florianopolis, SC, Brazil \\ ${ }^{\mathrm{C}}$ Instituto Nacional de Ciência e Tecnologia do CNPq. INCT de Energia e Ambiente, Universidade Federal de Bahia, Salvador, BA, Brazil
}

\section{A R T I C L E I N F O}

\section{Article history:}

Received 24 August 2012

Received in revised form

5 October 2012

Accepted 5 October 2012

Available online 11 October 2012

Keywords:

Vanadium determination

GF AAS

HR-CS GF AAS

Chemical modifiers

Petroleum analysis

\begin{abstract}
A B S T R A C T
The aim of this work was to investigate the influence of magnesium acetylacetonate $(\mathrm{MgA})$ on the signal of organic forms of vanadium in xylene solution by graphite furnace atomic absorption spectrometry. MgA alone or mixed with palladium acetylacetonate (PdA) was considered as a chemical modifier. It has been found that MgA does not improve, but decreases significantly the integrated absorbance of $\mathrm{V}$ in the form of alkyl-aryl sulfonates, acetylacetonates, porphyrins and in lubricating oils, while its effect is negligible in the case of "dark products" from petroleum distillation, i.e., heavy oil fractions and residues. The decrease is also observed in the presence of Pd. The MgA (or MgA+PdA) effect on the integrated absorbance of $\mathrm{V}$ has been studied using the following variants: different ways of modifier application, various pyrolysis temperature, additional application of air ashing, preliminary pretreatment with iodine and methyltrioctylammonium chloride, application of various graphite furnace heating systems (longitudinal or transverse) and various optical and background correction systems (medium-resolution line source spectrometer with deuterium background correction or highresolution continuum source spectrometer). The experiments indicate formation of more refractory compounds as a possible reason for the decrease of the integrated absorbance for some forms of $\mathrm{V}$ in the presence of MgA. The application of $\mathrm{MgA}$ as a chemical modifier in $\mathrm{V}$ determination is not recommended. Results of this work have general importance as, apart from the intentional use of MgA as a modifier, organic $\mathrm{Mg}$ compounds, present in petroleum products for other reason (e.g. as an additive), can influence the signal of $\mathrm{V}$ compounds and hence the accuracy in $\mathrm{V}$ determination. Generally, petroleum products with known amount of $\mathrm{V}$ are recommended as standards; however, lubricating oils can be inadequate for "dark products" from petroleum distillation. In the case of unknown samples it is recommended to check the effect of $\mathrm{Mg}$ using recovery tests of $\mathrm{V}$ in a form that is affected by MgA.
\end{abstract}

(c) 2012 Elsevier B.V. All rights reserved.

\section{Introduction}

Magnesium nitrate is traditionally applied as an ashing aid in procedures of dry mineralization of organic and biological samples, as $\mathrm{Mg}$ compounds are capable of preventing volatilization losses of some metals [1]. In graphite furnace atomic absorption spectrometry (GF AAS) magnesium nitrate was proposed as a chemical modifier in 1982 [2] to permit higher pyrolysis and atomization temperatures, in order to reduce interferences. Nowadays $\mathrm{Mg}$ nitrate is probably one of the most widely applied chemical modifiers in GF AAS. Generally, Mg nitrate improves thermal stability of analytes of high and medium

\footnotetext{
*Corresponding author. Tel.: +48 604569041; fax: +48 243653307.

E-mail addresses: zofia.kowalewskah@gmail.com, zofia.kowalewska@obr.pl (Z. Kowalewska).
}

volatility, and enhances the effect of Pd and other modifiers. MgO, which is formed as a result of the decomposition of the nitrate $\left(350-440{ }^{\circ} \mathrm{C}\right)[2-4]$ can physically adsorb/imbed analyte atoms or bind their oxides into stable mixed oxides of the spinell type. Isomorphism of the analyte compound and $\mathrm{MgO}$ can play an important role in the inclusion of the analyte in the structure of the modifier [5].

Mass spectrometric investigations conducted for some metals suggest that hydration of $\mathrm{MgO}$ depletes water in the atomizer, prevents analyte hydroxide formation and loss of volatile analyte hydroxides [6,7]. On the other hand, $\mathrm{MgO}$ can oxidize more volatile analyte forms into less volatile ones [7].

Majidi et al. [8,9] reviewed the application of molecular absorption spectrometry, thermogravimetric analysis, laser desorption mass spectrometry and differential scanning calorimetry for the investigation of $\mathrm{Mg}\left(\mathrm{NO}_{3}\right)_{2}$ vaporization from graphite, $\mathrm{Pt}(\mathrm{Al})$ and Ta substrates. Several carbides and oxides, as well as 
mixed compounds, such as $\mathrm{MgO}_{3} \mathrm{C}$ were observed in the solid phase. The formation of Grignard reagent-type compounds was anticipated.

Prell et al. [10] used AAS and mass spectrometry to investigate vaporization of Group IIA elements in nitrogen and in vacuum; they distinguished three types of sites on the graphite surface. The analyte, depending on which site it is bound, can be volatilized as a carbide or oxide, and at lower or at higher temperature, due to weaker or stronger interaction with the graphite. Atomization of $\mathrm{Mg}$ is the result of dissociative adsorption of the magnesium oxide; free $\mathrm{Mg}$ atoms and high-temperature carbides appear as a result of disturbances (Frank-Condon splitting) of the surface states of absorbed substances [10]. The authors also stated that a higher volume of investigated solution results in greater analyte dispersion and increased low-temperature carbide formation.

Katskov et al. [11,12] investigated the evaporation of $\mathrm{Mg}\left(\mathrm{NO}_{3}\right)_{2}$ and observed faster vapor release in pyrocoated than in Ta-lined tubes, which was correlated with light scattering. The experimental data showed a radial thermal gradient over the cross-section of the pyrocoated tube simultaneously with the vaporization of $\mathrm{MgO}$, which was attributed to the reaction of the sample vapor with the graphite. As a result, the spatial condensation of the sample vapor induces the light scattering.

Rohr et al. [3] investigated corrosion phenomena in the graphite furnace and expected strong corrosion in the case of $\mathrm{Mg}\left(\mathrm{NO}_{3}\right)_{2}$ vaporization as a result of $\mathrm{MgO}$ interaction with graphite, but the effect was moderate. On the other hand, a pronounced tendency to massive secondary carbon deposition at all places of lower temperature was observed (e.g. the gap between the platform and the lower tube wall was totally filled with secondary carbon). The authors also anticipated that $\mathrm{Mg}$ vapor, resulting from the reduction of $\mathrm{MgO}$ above $2000{ }^{\circ} \mathrm{C}$, would decrease significantly the oxygen partial pressure, thereby enhancing the atomization of analytes with high affinity to oxygen.

It is known that $\mathrm{MgCl}_{2}$ is hydrolyzed in the graphite furnace, but the work of Daminelli et al. [13] showed that $\mathrm{Mg}$ is not only present in the form of $\mathrm{MgO}$; the distribution of $\mathrm{Mg}$ between its various forms as $\mathrm{MgCl}_{2}, \mathrm{MgCl}$ and $\mathrm{MgO}$ is affected by the temperature program, the internal gas and the surface of vaporization (Ta or graphite).

All of the above examples show a significant role of the graphite surface as well as the complexity of $\mathrm{Mg}$ interaction with graphite. The importance of graphite for modifier action was strongly emphasized in a review by Ortner et al. [14], devoted to modifiers and coatings in GF AAS. The authors considered various aspects of modifier and analyte interaction with graphite, such as carbide and/or intercalation compound formation as well as penetration into the pyrolytic graphite. Differences in penetration depth and interaction strength between $\mathrm{Mg}$ and Pd were stated; leaching experiments with $6 \mathrm{~mol} \mathrm{~L}^{-1} \mathrm{HCl}$ showed that the recovery from graphite after drying was $100 \%$ in the case of $\mathrm{Mg}$, but only $20 \%$ in the case of Pd $[14,15]$.

A mixture of Pd and Mg nitrates is the most widely applied, so called "universal modifier" as it is effective for the thermal stabilization of more than 20 elements [16,17]. Qiao and Jackson [18] used scanning electron microscopy to explain the modifier action. They speculated that Pd exhibits mainly a physical mechanism, and the addition of $\mathrm{Mg}\left(\mathrm{NO}_{3}\right)_{2}$ significantly influences the distribution of Pd in/on graphite, which results in an enhancement of atomization. On the other hand, Xiao-Quan and Bei [19] did not recommend the addition of $\mathrm{Mg}\left(\mathrm{NO}_{3}\right)_{2}$ to the Pd modifier due to the increased background absorption in the presence of this modifier, compared to Pd alone or mixed with ascorbic acid.

Vanadium is the most abundant metal present in petroleum, and it has to be determined in a wide variety of samples from the petroleum industry [20-36]. Vanadium is a refractory metal with a melting point of $1730{ }^{\circ} \mathrm{C}$ and a boiling point of $3000{ }^{\circ} \mathrm{C}$. In the graphite furnace it is present in the form of carbides or oxides, so that normally relatively high pyrolysis temperatures can be applied [37-41]. The higher oxides can be reduced to lower oxides and carbides or dissociated. For example, $\mathrm{VO}$ and $\mathrm{VO}_{2}$ were detected in the gas phase by mass spectrometry [40] and $\mathrm{X}$-ray diffraction experiments indicated only the presence of VC above $1200{ }^{\circ} \mathrm{C}$ [37]. The $\mathrm{V}$ compounds formed in a graphite furnace are not particularly stable, so that $\mathrm{V}$ can be determined relatively easily by GF AAS [41]. The V atomization can be a thermal decomposition of the solid VC carbide [37,38], a thermal decomposition of $\mathrm{VO}_{(\mathrm{g})}$ [39], or a sublimation of $\mathrm{V}$ from the solid phase [41,42]. Fast furnace heating, good pyrolytic coating and high atomization temperature are recommended for the atomization of $\mathrm{V}[41,43]$.

The atomization temperatures available in graphite furnace systems might be too low to obtain a plateau in the atomization curve of $\mathrm{V}$ [35], principally in longitudinally heated nonisothermal furnaces. In the presence of matrix the formation of mixed carbides, which include VC, could be troublesome, as the atomization of $\mathrm{V}$ from mixed carbides might need higher temperatures [44]. The formation of ternary refractory compounds was considered in the presence of $\mathrm{Ta}, \mathrm{Si}, \mathrm{Nb}, \mathrm{Zr}, \mathrm{W}$, La and Mo [20,43-45].

In some cases the determination of $\mathrm{V}$ does not need any chemical modifier $[20-25,27,28]$. On the other hand, if $\mathrm{V}$ is present in a volatile form, such as $\mathrm{V}$ porphyrins, which can be lost at temperatures even below $400{ }^{\circ} \mathrm{C}[27-30,32,35]$, thermal stabilization is indispensable. Pd was most often used for thermal stabilization of $\mathrm{V}$ in the analysis of petroleum products $[26,27,29,30,35]$, only Thomaidis and Piperaki [34] recommended Pt.

Magnesium nitrate, which is a popular modifier for many elements and matrices, was also applied successfully for some determinations of $\mathrm{V}$ in aqueous solutions $[41,44]$. However, it was found as inadequate for the analysis of petroleum products [26,34]. In the case of multi-element Conostan oil (as a sample), using $\mathrm{Mg}\left(\mathrm{NO}_{3}\right)_{2}$, the sensitivity and precision was worse than using Pt [34]. Much worse results were obtained with $\mathrm{Mg}\left(\mathrm{NO}_{3}\right)_{2}$ as a modifier in the analysis of emulsions of petroleum [26]; because of formation of a precipitate (probably asphaltenes), the modifier could not be applied for sample analysis.

In some of our earlier work, devoted to the determination of other elements in xylene solution of petroleum products, $\mathrm{Mg}$ acetylacetonate (MgA) was successfully applied as part of a modifier system. MgA, added to Pd acetylacetonate (PdA) solution, significantly increased the integrated absorbance of $\mathrm{Pb}$ in S21 multielement Conostan oil standard, $\mathrm{Pb}$ in $1634 \mathrm{~b}$ oil and tetraethyllead [46], and it also added to thermal stabilization of the analyte. The addition of MgA to the PdA modifier turned out to be indispensable for the quantitative determination of $S$ in a polysulfide form using graphite furnace molecular absorption spectrometry [47].

In our earlier work devoted to $\mathrm{V}$ determination in xylene solution, the varying behavior and volatility of different $\mathrm{V}$ compounds were overcome by chemical modification. Air ashing and Pd (the Pd solution injected into GF together with the sample solution) were recommended for porphyrins and petroleum products, while for the compounds containing $\mathrm{O}$ as a donor atom the pretreatment with iodine followed by methyltrioctylamonium chloride was necessary. No universal modifier could be found.

The main aim of the present work was to investigate the influence of MgA on the GF AAS signal of $\mathrm{V}$ to evaluate the feasibility of MgA as a single modifier or with PdA as a mixed modifier for the determination of $\mathrm{V}$ in xylene solutions of organic compounds and petroleum products. It was expected that MgA 
would decompose with the formation of $\mathrm{MgO}$, similar to $\mathrm{Mg}\left(\mathrm{NO}_{3}\right)_{2}$ in an aqueous solution. $\mathrm{MgO}$ can imbed the analyte, and its oxidizing properties can be also important. $\mathrm{MgA}$ is soluble in xylene, in contrast to $\mathrm{Mg}\left(\mathrm{NO}_{3}\right)_{2}$, which enables full autosampler utilization. It is also important to take into account that organic $\mathrm{Mg}$ compounds can be present in petroleum products. Native Mg, originating from crude oil is usually present only at the $\mathrm{mg} \mathrm{kg}^{-1}$ or tens of $\mathrm{mg} \mathrm{kg}^{-1}$ level in petroleum products [48]. Mg can however appear in significant amount in lubricating oil as a result of gears or shafts failure or as an additive purposely used, e.g. as an anticorrosion aid $[49,50]$.

\section{Experimental}

\subsection{Instrumentation and operation}

Most of the experiments were carried out using Solar $939 \mathrm{QZ}$ (Unicam, Cambridge, GB) or Solaar M (Thermo Electron, Walham, USA) medium-resolution line source atomic absorption spectrometers (LS AAS). Both instruments were equipped with longitudinally heated graphite furnaces and furnace autosamplers (FS90 and FS95, respectively); pyrolytically coated extended-life (ELC) graphite tubes without platform were used exclusively. A vanadium hollow cathode lamp and the 318.5-nm analytical line were used with a $0.2-\mathrm{nm}$ bandpass. Deuterium lamp background correction was used throughout. As the same graphite furnace and the same tubes are used in the two instruments, no distinction will be made which instrument has been used for which experiment.

A Model contrAA 700 (Analytik Jena, Jena, Germany) highresolution continuum source atomic absorption spectrometer (HR-CS AAS) [51] was used for some of the experiments. It is equipped with a high-intensity xenon short-arc lamp, operating in "hot-spot" mode, as a radiation source, a high-resolution double monochromator, consisting of a prism pre-monochromator and an echelle grating monochromator, a linear charge-coupled device array detector and an MPE60 autosampler. The measurement range was $318.223-318.572 \mathrm{~nm}$, and the $\mathrm{V}$ absorption was measured at the 318.398-nm line using 3 evaluation pixels and dynamic background correction. The resolution is better than $2 \mathrm{pm}$ per pixel. The spectrometer was equipped with a pyrolytically coated graphite tube without a platform (Analytik Jena, Part No. 407-152.012), which was transversely heated.

\subsection{Reagents and samples}

Xylene (p.a., OBR PR S.A., Płock, Poland) was used as the organic solvent throughout this work. Pyridine (Sigma Aldrich, Germany), acetonitrile (Baker, Holland), 2-ethylhexanoic acid and 6-methyl-2,4-heptane-dione (Sigma Chemicals Co., USA) were applied in some cases to improve dissolution of metal-organic compounds.

Magnesium(II) acetylacetonate, MgA, and palladium(II) acetylacetonate, PdA, (Sigma Aldrich, St. Louis, USA), iodine and methyltrioctylammonium chloride, $\mathrm{MTOACl}$, (POCh, Gliwice, Poland) were used as chemical modifiers. MgA was used as a $0.1 \%$ (relative to $\mathrm{Mg}$ ) xylene solution. Pd was used in the form of xylene oversaturated solution (Pd calculated concentration: $0.2 \%$ $\mathrm{m} / \mathrm{v}$ ). The $\mathrm{Pd}+\mathrm{Mg}$ modifier contained also $0.1 \% \mathrm{~m} / \mathrm{v} \mathrm{Mg}$ as $\mathrm{MgA}$. To improve dissolution 2-ethylhexanoic acid and gentle heating were applied. The solution was prepared daily. Iodine and $\mathrm{MTOACl}$ were used as $1 \% \mathrm{~m} / \mathrm{v}$ solutions in xylene.

The investigated vanadium forms and samples are listed in Table 1. S21 multielement oil Conostan standard containing $500 \mathrm{mg} \mathrm{kg}^{-1} \mathrm{~V}$ and VCN single oil Conostan standard containing
$5000 \mathrm{mg} \mathrm{kg}^{-1} \mathrm{~V}$ were from Conoco Specialty Products (USA), VB from Carlo Erba (Milan, Italy) and VA3, VA4, VPh and VPt from Aldrich (Germany).

The certified reference materials (CRM) NIST SRM 1085b lubricating oil and NIST SRM 1634b and 1634c fuel oils were from the National Institute for Standards and Technology (Gaithersburg, MD, USA) and the CRM HU-1 lubricating oil was from SCP Science (Clark Graham, Canada). The S1-S2 vacuum distillates came from a crude oil refinery. Nothing is known on the form of V in the CRM and S1-S2 samples. Fuel oils and vacuum distillates were melted in a dryer at $50-80{ }^{\circ} \mathrm{C}$ before dissolution.

All compounds and samples specified in Table 1 were investigated as xylene solutions. The stock solutions of $\mathrm{V}$ compounds were prepared to contain $50-100 \mathrm{mg} \mathrm{kg}^{-1} \mathrm{~V}$. There was no problem with the solubility of Conostan standards, CRM and S1-S2 samples in xylene. To improve dissolution of the other compounds 2-ethylhexanoic acid (for VA3, VA4, VB, VPt and VPh), 6-methyl-heptane-dione (for VB), pyridine and acetonitrile (for VPh and VPt) were used. VA3 and VA4 dissolved easily without heating. The other compounds dissolved after gentle heating. The stock solutions of the $V$ compounds were homogenous for at least one month. The solutions of the different $\mathrm{V}$ forms were prepared daily from stock solutions to contain $\mathrm{V}$ in the concentration range $0.050-0.200 \mathrm{mg} \mathrm{kg}^{-1}$.

\subsection{Procedure}

The graphite furnace temperature program is shown in Table 2 for LS AAS and Table 3 for HR-CS AAS. In some cases air was applied as the internal gas instead of argon. The volume of the solution for measurement and of the modifier was $8 \mu \mathrm{l}$, unless indicated differently.

The modifiers were applied in the following ways:

(i) "wet" way (further abbreviation "w", e.g. $\mathrm{Pd}_{w}$ ): the sample and the modifier solutions were taken into the autosampler capillary and injected into graphite furnace together; in fact the modifier is taken before the sample, thus, it is injected over the sample;

(ii) "dry first" mode (further abbreviation "df", e.g. $\mathrm{Pd}_{\mathrm{df}}$ ): the injection of the sample solution was preceded by the injection and thermal pretreatment of the modifier solution (the steps 1, 2 and 5 in Table 2 without air ashing or the steps 1-5 with air ashing); afterwards the entire heating program (as in "wet" mode) was performed.

(iii) "dry last" mode (further abbreviation "dl", e.g. $\mathrm{Pd}_{\mathrm{dl}}$ ): the injection of the sample solution preceded the injection of the modifier solution; after the injection of sample solution the shortened furnace heating was applied (i.e., the steps 1,2 and 5 without air ashing or the steps 1-5 with air ashing); after modifier injection the whole heating program (as in "wet" mode) was performed.

The contrAA 700 was used for comparison; therefore the same modifier application mode as in the case of Solar had to be applied. The mode "to sample" of the modifier use, offered by the contrAA software was not appropriate as the modifier was taken to the autosampler capillary after the sample and injected before the sample. To reach "wet" mode of modifier application for the contrAA exactly in the same way as for the Solars, the modifier application should be selected, but the option "to sample" should not be selected.

The experiments with iodine and $\mathrm{MTOACl}\left(\mathrm{I}_{2}+\mathrm{MTOACl}\right)$ were done as described in the previous work [35]. 
Table 1

Organic V compounds, Certified Reference Materials (CRM) and petroleum products used in the present investigation.

\begin{tabular}{|c|c|c|c|}
\hline Used abbreviation & & Donor atom & $\mathrm{V}$ content $\left(\mathrm{mg} \mathrm{kg}^{-1}\right)$ \\
\hline \multicolumn{4}{|c|}{ Defined organic compounds } \\
\hline S21 & Vanadium(V) alkyl-aryl sulfonate (in multielement oil standard) & $\mathrm{O}$ & \\
\hline SCPK & ( $\mathrm{V}$ in multielement oil standard) & Unknown & \\
\hline VCN & Vanadium(V) alkyl-aryl sulfonate & $\mathrm{O}$ & \\
\hline VB & Bis(1-phenyl-1,3-butanedione)oxovanadium & 0 & \\
\hline VA3 & Vanadium(III) acetyloacetonate & $\mathrm{O}$ & \\
\hline VA4 & Vanadium(IV)-oxy acetyloacetonate & $\mathrm{O}$ & \\
\hline $\mathrm{VPh}$ & 2,3,7,8,12,13,17,18-octaehtyl-21H, $23 \mathrm{H}$-porphine vanadium(IV) oxide & $\mathrm{N}$ & \\
\hline VPt & 5,10,15,20-tetraphenyl-21H,23H-porphine vanadium(IV) oxide & $\mathrm{N}$ & \\
\hline \multicolumn{4}{|c|}{ (2) } \\
\hline $1085 b$ & (CRM) Wear-metals in lubricating oil & Unknown & $297.8 \pm 4.6$ \\
\hline HU & (CRM) Used oil, fortified with metals & Unknown & $7.0 \pm 0.5$ \\
\hline $1634 b$ & (CRM) Fuel oil & Unknown & $55.4 \pm 1.1$ \\
\hline $1634 \mathrm{c}$ & (CRM) Fuel oil & Unknown & $28.19 \pm 0.40$ \\
\hline S1 & Vacuum distillate-catalytic cracking feed & Unknown & $0.41 \pm 0.04$ \\
\hline S2 & Vacuum distillate-catalytic cracking feed & Unknown & $1.12 \pm 0.11$ \\
\hline
\end{tabular}

Table 2

Graphite furnace temperature program for LS AAS (Solar 939 or Solaar "M").

\begin{tabular}{llllll}
\hline Step & $\begin{array}{l}\text { Temperature } \\
\left({ }^{\circ} \mathrm{C}\right)\end{array}$ & $\begin{array}{l}\text { Ramp } \\
\left({ }^{\circ} \mathrm{C} \mathrm{s}^{-1}\right)\end{array}$ & $\begin{array}{l}\text { Hold time } \\
(\mathrm{s})\end{array}$ & $\begin{array}{l}\text { Internal } \\
\text { gas }\end{array}$ & $\begin{array}{l}\text { Internal gas flow rate } \\
\left(\mathrm{L} \mathrm{min}^{-1}\right)\end{array}$ \\
\hline 1 & 140 & 30 & 10 & Argon & 0.2 \\
2 & 270 & 20 & 20 & Argon & 0.2 \\
$3^{\mathrm{a}}$ & 500 & 50 & 10 & Air & 0.2 \\
$4^{\mathrm{a}}$ & 500 & 50 & 10 & Argon & 0.2 \\
$5^{\mathrm{b}}$ & 1200 & 100 & 30 & Argon & 0.2 \\
$6^{\mathrm{c}}$ & 2850 & $>2000$ & 5 & Argon & 0 \\
7 & 2850 & $>2000$ & 5 & Argon & 0.3 \\
\hline
\end{tabular}

a Omitted when air ashing was not applied.

b Last step of thermal pretreatment in $\mathrm{Pd}_{\mathrm{df}}$ mode.

${ }^{\mathrm{c}}$ Atomization and read step.

Table 3

Graphite furnace temperature program for HR-CS AAS (contrAA 700).

\begin{tabular}{llclll}
\hline $\begin{array}{l}\text { Step } \\
\text { number }\end{array}$ & $\begin{array}{l}\text { Temperature, } \\
\left({ }^{\circ} \mathrm{C}\right)\end{array}$ & $\begin{array}{l}\text { Heating rate, } \\
\left({ }^{\circ} \mathrm{C} \mathrm{s}^{-1}\right)\end{array}$ & $\begin{array}{l}\text { Hold } \\
\text { time }(\mathrm{s})\end{array}$ & $\begin{array}{l}\text { Internal } \\
\text { gas }\end{array}$ & $\begin{array}{l}\text { Internal gas flow } \\
\text { rate }\left(\mathrm{L} \mathrm{min}^{-1}\right)\end{array}$ \\
\hline 1 & 100 & 30 & 15 & Argon & 2.0 \\
2 & 140 & 30 & 15 & Argon & 2.0 \\
3 & 270 & 30 & 15 & Argon & 2.0 \\
$4^{\mathrm{a}}$ & 500 & 50 & 10 & Air & 2.0 \\
$5^{\mathrm{a}}$ & 500 & 0 & 10 & Argon & 2.0 \\
6 & 1200 & 100 & 30 & Argon & 2.0 \\
$7^{\mathrm{b}}$ & 1200 & 0 & 5 & Argon & 0.0 \\
$8^{\mathrm{c}}$ & 2500 & 2000 & 5 & Argon & 0.0 \\
9 & 2600 & 500 & 4 & Argon & 2.0 \\
\hline
\end{tabular}

a Omitted when air ashing was not applied.

b Last step of thermal pretreatment in $\mathrm{Pd}_{\mathrm{df}}$ mode.

${ }^{c}$ Atomization and read step.

\section{Results and discussion}

Most of the experiments carried out in this work have comparative character. As a variety of compounds has been analyzed in different variants over an extended period of time, it is not possible to make one comparison only. Therefore, two to four signals obtained for a compound/sample under given conditions will be presented to show a certain effect or behavior. Also, each figure should be considered independently.

\subsection{Experiments without and with $M g A$}

To evaluate the influence of $\mathrm{MgA}$ on the signal of various organic $\mathrm{V}$ forms, the results of measurements without any modifier and with $\mathrm{MgA}$ injected with the sample solution $\left(\mathrm{Mg}_{\mathrm{w}}\right)$ are compared in Fig. 1a. MgA has no significant influence on the integrated absorbance of $\mathrm{V}$ in heavy petroleum products (1634b, $1634 \mathrm{c}$ and S2), but it strongly decreases the integrated absorbance of $\mathrm{V}$ in all single compounds. MgA also decreases the integrated absorbance of $\mathrm{V}$ in lubricating oils; the effect is very pronounced in the case of $1085 \mathrm{~b}$ and moderate in the case of HU oil.

MgA was also introduced to the PdA solution and the measurements using only $\mathrm{PdA}\left(\mathrm{Pd}_{\mathrm{w}}\right)$ and using the mixed modifier solution $(\mathrm{Pd}+\mathrm{Mg})_{\mathrm{w}}$ are compared in Fig. 1b. In most cases the effect of MgA on the integrated absorbance of $\mathrm{V}$ is similar in the absence and in the presence of PdA; however, distinct differences are observed for VPh and VPt porphyrins. Pd stabilizes the porphyrins thermally (which was shown already in previous work [35]) and diminishes the influence of Mg on their signals. For example, Mg diminishes the integrated absorbance of VPh by more than $80 \%$ without Pd (Fig. 1a) and by only about $40 \%$ with Pd (Fig. 1b). For VPt the numbers are $79 \%$ and $27 \%$, respectively. In contrast, Pd does not help to reduce the influence of $\mathrm{Mg}$ on the determination of $\mathrm{V}$ in the other single compounds. It was found in previous work [35] that $\mathrm{Pd}_{\mathrm{w}}$ used as a single modifier can even diminish the signal of V in VA3 and VA4 upto 50\% in comparison with experiments without a modifier.

The influence of an increasing mass of $\mathrm{Mg}$ as $\mathrm{MgA}$ on the integrated absorbance of $\mathrm{V}$ in the absence and in the presence of PdA is shown in Fig. 2a and $2 b$, respectively. It can be seen that in both cases an increasing amount of $\mathrm{Mg}$ leads to a decrease of the signal for $\mathrm{V}$ present as a single compound and in lubricating oil. The only exceptions are the CRM 1634c and the sample S2, which exhibit only a minor or no effect due to the presence of Mg. For all other samples or individual compounds, the strongest effect is obtained for the addition of a low mass of $\mathrm{Mg}(8 \mu \mathrm{g})$, with a significantly smaller additional effect for a higher mass ( $16 \mu \mathrm{g})$.

Generally, the application of $8 \mu \mathrm{g}$ of $\mathrm{MgA}$ (the amount used mainly in this work) does not significantly influence the shape and position of the $\mathrm{V}$ peak in comparison with the peak measured without Mg. The uncertainty of the position of the peak maximum is at the level of $0.05 \mathrm{~s}$. However, when signals for higher Mg mass are taken into account, some small $(0.1 \mathrm{~s})$ delay of $\mathrm{V}$ atoms appearance and peak maximum location can be observed, as it is shown for the S21 sample in Fig. 3. On the other hand, the V atoms appearance time and the integrated absorbance do not change significantly in the case of heavy petroleum products, such as $1634 \mathrm{c}$ oil (Fig. 3). The delay of the $\mathrm{V}$ peak with simultaneous decrease of the integrated absorbance might suggest formation of more refractory $\mathrm{V}$ compounds, which are more 

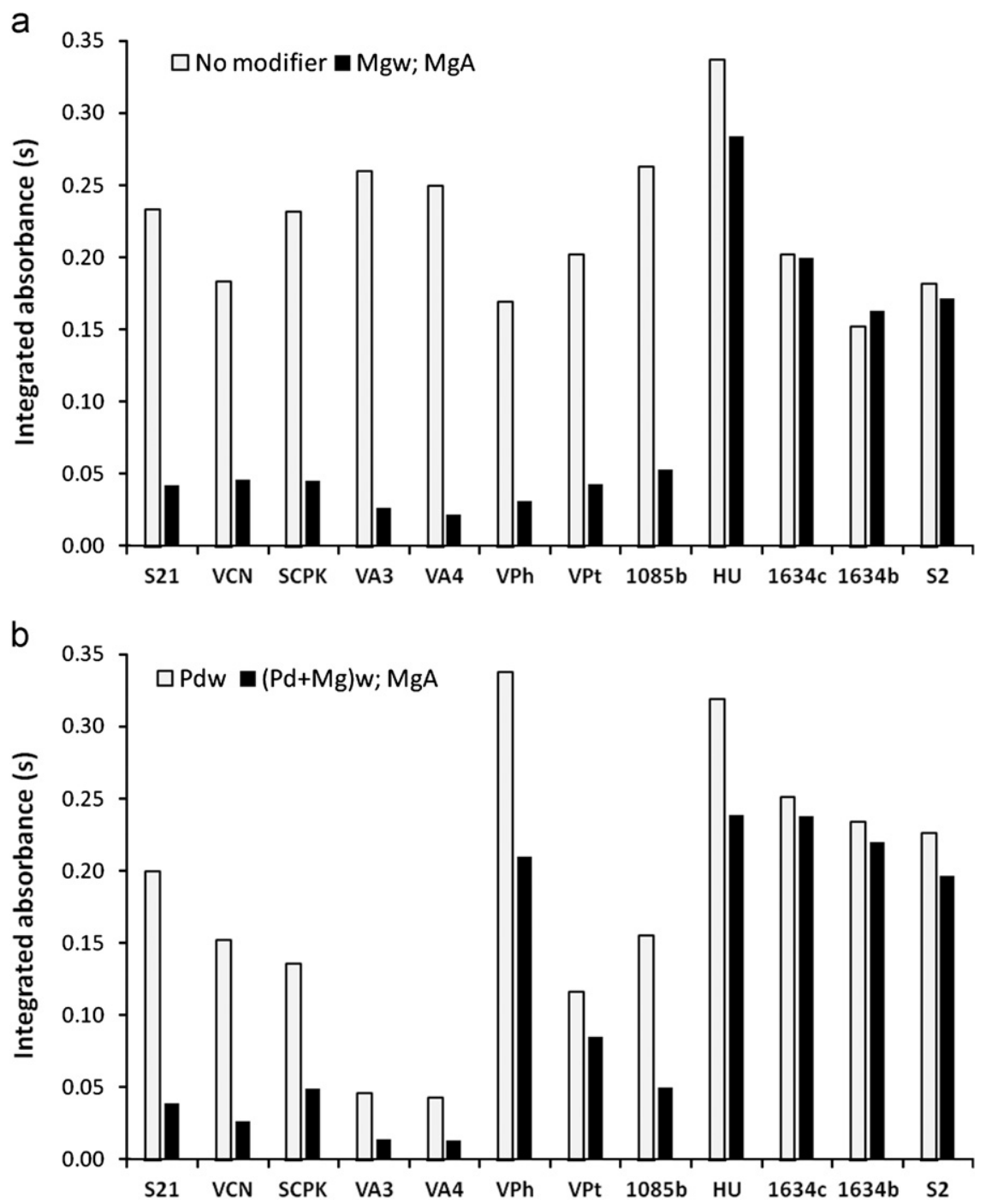

Fig. 1. Influence of MgA application on the integrated absorbance of $V$ in experiments without $\operatorname{Pd}(1 \mathrm{a})$ or with $\mathrm{Pd}(1 \mathrm{~b})$.
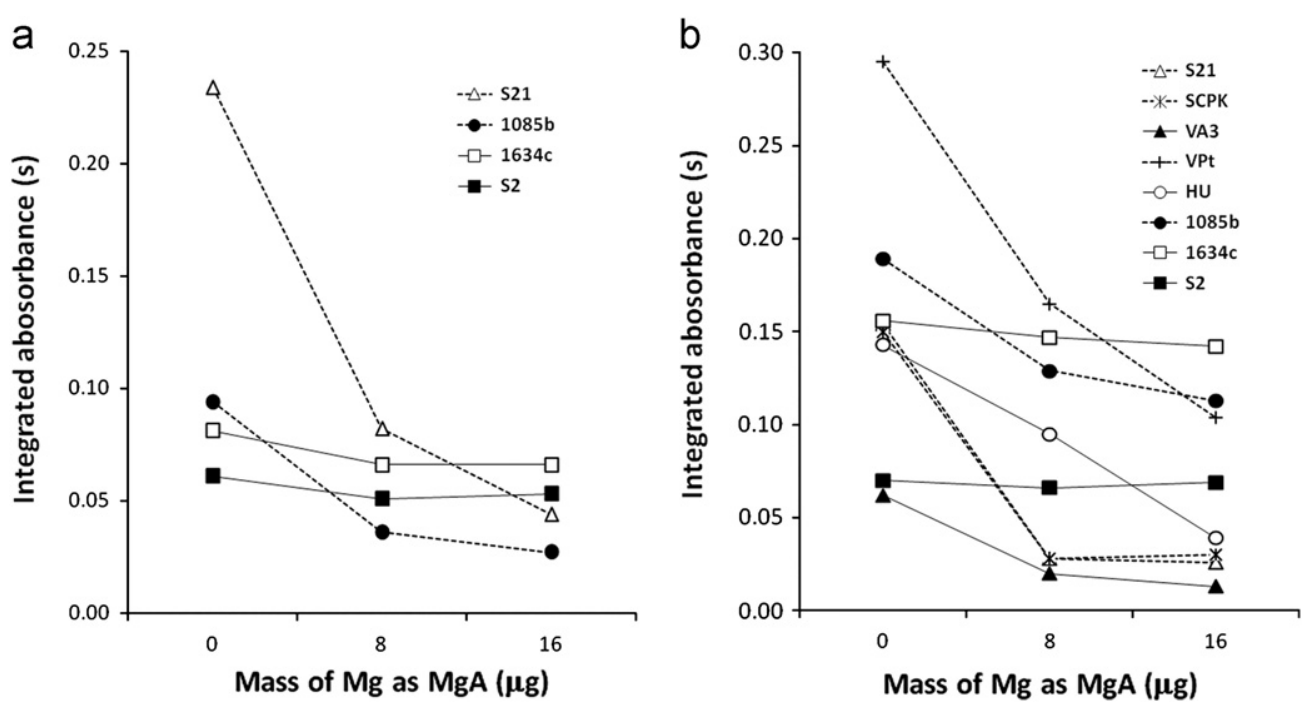

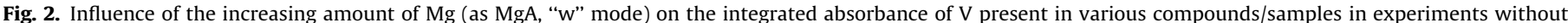
Pd (2a) or with Pd (2b). 

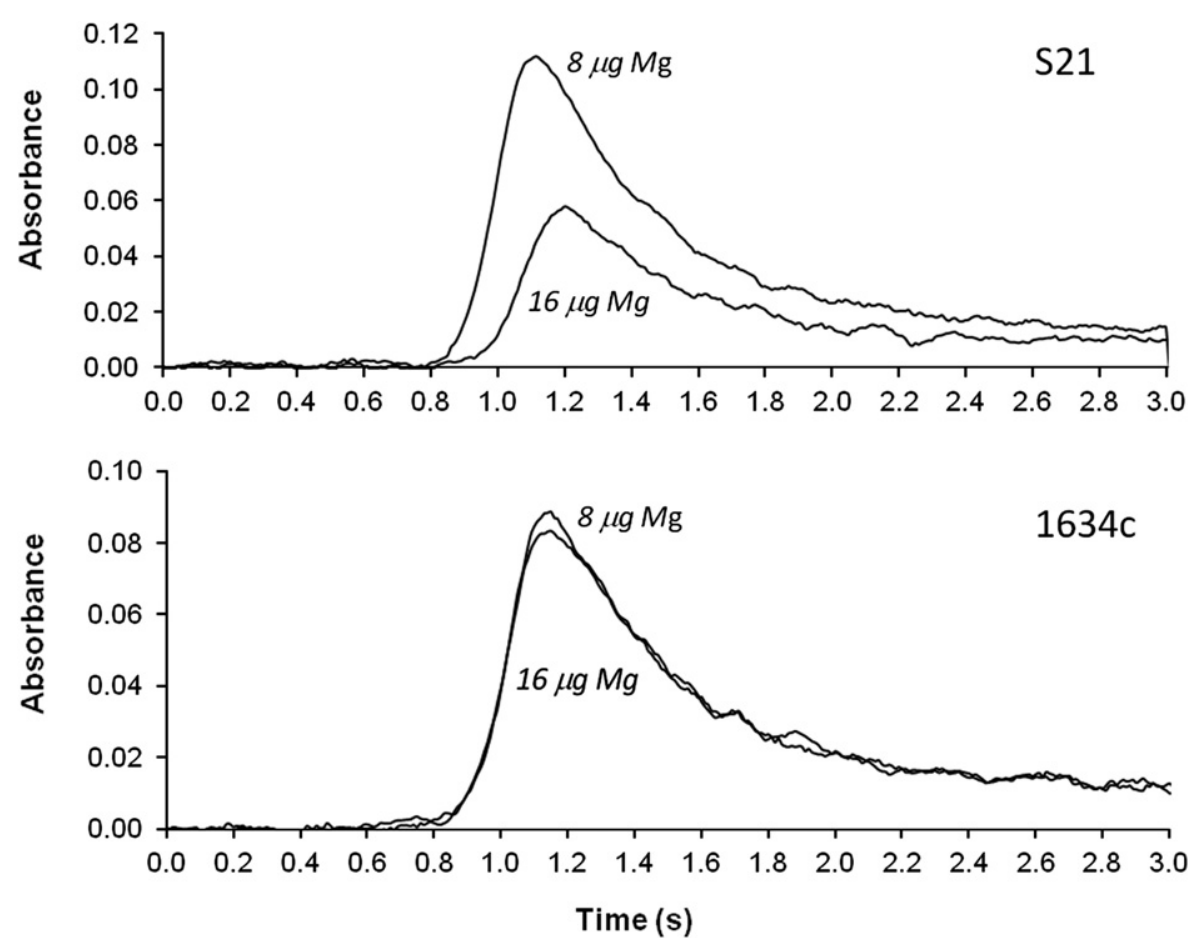

Fig. 3. Examples of $\mathrm{V}$ signal with increasing amount of $\mathrm{Mg}$ (as $\mathrm{MgA}$ ).

difficult to atomize or do not atomize at all under the conditions used.

One of the explanations for the decreasing effect of MgA on the integrated absorbance of $\mathrm{V}$ could be the formation of relatively volatile acetylacetonates of $\mathrm{V}$ and their loss in the pyrolysis stage. The melting points of VA3 and VA4 are $181^{\circ} \mathrm{C}$ and $235{ }^{\circ} \mathrm{C}$, respectively. However, the high integrated absorbance values obtained for VA3 and VA4 without any modifier (Fig. 1a and [35]) make this assumption very unlikely, particularly as a pyrolysis temperature of $1200{ }^{\circ} \mathrm{C}$ was used in these investigations.

The possibility of losses by evaporation was also investigated by comparing of the integrated absorbance obtained after pyrolysis temperatures of $1200{ }^{\circ} \mathrm{C}$ and $300{ }^{\circ} \mathrm{C}$, respectively, in the experiment with $\mathrm{Mg}_{\mathrm{w}}$. Among the investigated samples, only in the case of VPh, an increase of the integrated absorbance by more than a factor of 2 was observed for the $300{ }^{\circ} \mathrm{C}$ pyrolysis temperature; for all the other samples the difference was negligible ( $<10 \%$ ). Thus, the significant decrease of the $\mathrm{V}$ signal in the presence of $\mathrm{MgA}\left(\mathrm{Mg}_{\mathrm{w}}\right)$ cannot be due to evaporation of volatile $\mathrm{V}$ forms.

\subsection{Effect of the way of modifier application}

It was found previously [35] that for the analysis of petroleum products and porphyrins the joint injection of the $\mathrm{Pd}$ and the sample solution is necessary ( $\mathrm{Pd}_{\mathrm{w}}$ mode). If $\mathrm{Pd}$ is injected and thermally pretreated before the injection of the sample solution, the modifier efficiency is limited and the integrated absorbance of $\mathrm{V}$ can be upto about $50 \%$ lower. The results of the investigation of the way of application of Mg modifiers on the integrated absorbance of $\mathrm{V}$ are presented in Figs. $4 \mathrm{a}-4 \mathrm{~d}$.

The comparison of $\mathrm{Mg}_{\mathrm{w}}$ and $\mathrm{Mg}_{\mathrm{df}}$ is shown in Fig. $4 \mathrm{a}$, and that between $(\mathrm{Pd}+\mathrm{Mg})_{\mathrm{w}}$ and $(\mathrm{Pd}+\mathrm{Mg})_{\mathrm{df}}$ in Fig. $4 \mathrm{~b}$; the latter one also contains results for the $(\mathrm{Pd}+\mathrm{Mg})_{\mathrm{dl}}$ variant, which will be discussed later. It is obvious that the mode of modifier application is much less important for heavy petroleum products. The contact between MgA and $\mathrm{V}$, present in the form of a single compound is of disadvantage, while the independent injection, drying and thermal pretreatment somehow protects the $\mathrm{V}$ compounds from the MgA influence. This is further observed in Fig. 4c, where comparison of $\mathrm{Pd}_{\mathrm{df}}$ and $(\mathrm{Pd}+\mathrm{Mg})_{\mathrm{df}}$ does not show a decrease of the $\mathrm{V}$ signal as a result of the additional $\mathrm{Mg}$ application, which is in contrast to $\mathrm{Pd}_{\mathrm{w}}$ and $(\mathrm{Pd}+\mathrm{Mg})_{\mathrm{w}}$ (see Fig. 1b). Moreover, for VPt, the addition of $\mathrm{MgA}$ even appears to be advantageous. Fig. $4 \mathrm{c}$ also contains data of the $\operatorname{Pd}_{w}$ variant and shows that $\mathrm{Pd}$ as $\operatorname{Pd}_{w}$ is advantageous for the analysis of VPt porphyrin, 1634c oil and S2 heavy petroleum product.

Fig. $4 \mathrm{~b}$ also shows the results for the third variant of $\mathrm{Pd}+\mathrm{Mg}$ application, the thermal pretreatment of the sample before the modifier injection $\left((\mathrm{Pd}+\mathrm{Mg})_{\mathrm{dl}}\right)$. There is no single case where injection of the sample before the modifier solution could be advantageous. In the case of volatile V forms (e.g. VPt), V could be lost by evaporation before the modifier starts to act.

In the case of mixed modifiers there are two application possibilities: the introduction of both modifiers in one solution (e.g. $\left.(\mathrm{Pd}+\mathrm{Mg})_{\mathrm{w}}\right)$ or the independent application in two separate solutions (e.g. $\mathrm{Pd}_{\mathrm{w}}+\mathrm{Mg}_{\mathrm{w}}$ ). In this work mainly the first variant was applied, but in Fig. 4d both variants are compared, revealing significant differences. It is evident that the interaction $\mathrm{V}$ compound-MgA-PdA takes place in the solution. Therefore, the effect of $\mathrm{Pd}_{\mathrm{w}}+\mathrm{Mg}_{\mathrm{w}}$ relative to $\mathrm{Pd}_{\mathrm{w}}$ is weaker than the effect of $(\mathrm{Pd}+\mathrm{Mg})_{\mathrm{W}}$.

The effect of the way in which the modifiers are applied appears to confirm the formation of more refractory $V$ compounds in the presence of $\mathrm{MgA}$ and the importance of graphite in the observed processes. Successive injection of solutions can result in variations in the location of the injected compounds, the decreased formation of more refractory compounds containing $\mathrm{V}$ and an increase of the integrated absorbance of $\mathrm{V}$. This explanation appears to be valid for Fig. 4d, as well as for the comparison of "df" with "w" and "dl" with "w" variants (Fig. 4a and $4 \mathrm{~b}$ ). The exceptions are VPt, 1634c and S2, samples that contain volatile $\mathrm{V}$ forms which need at least the application of Pd for thermal stabilization and the joint injection of sample and 

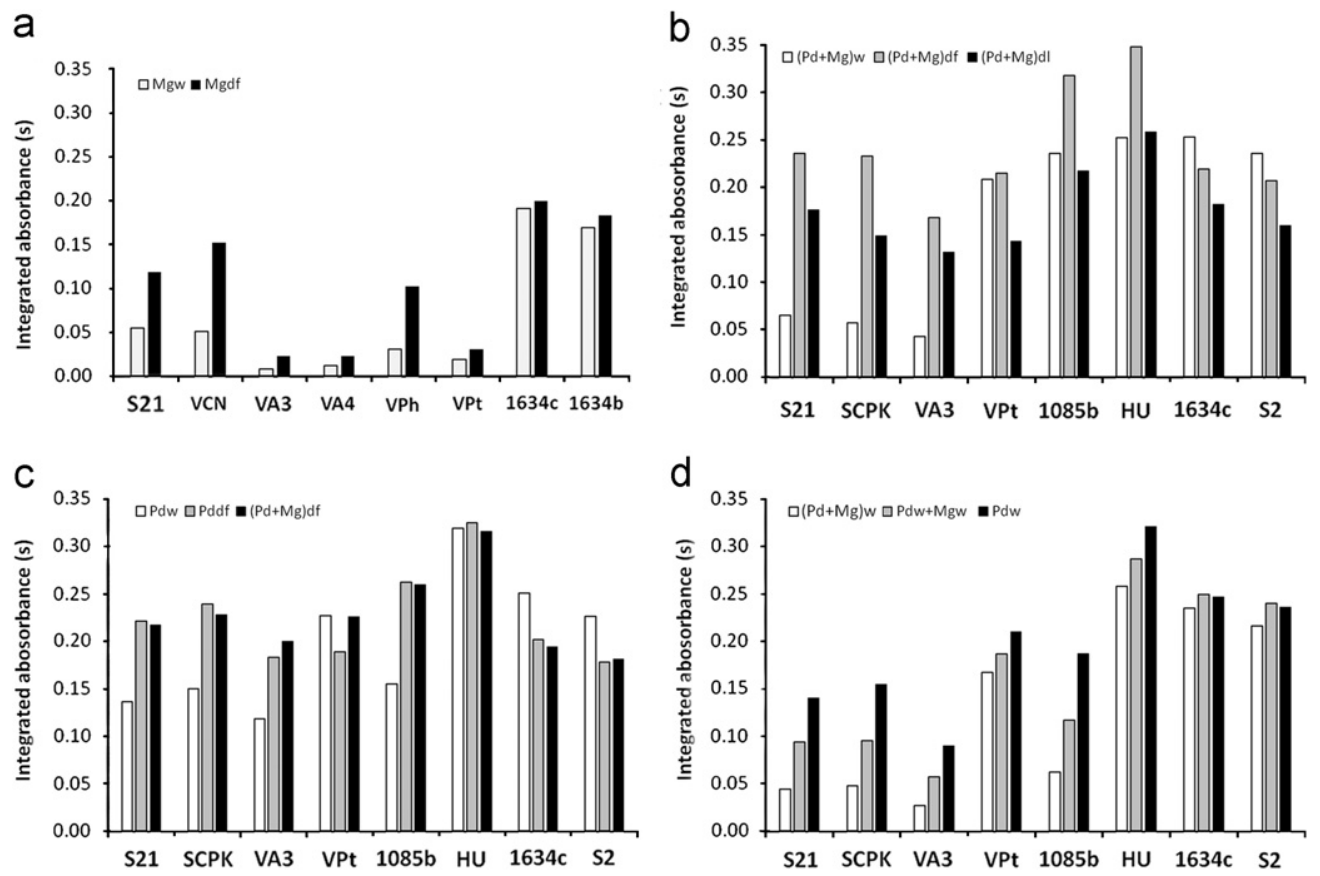

Fig. 4. (4a-4d) Influence of modifier application way on the integrated absorbance of V.

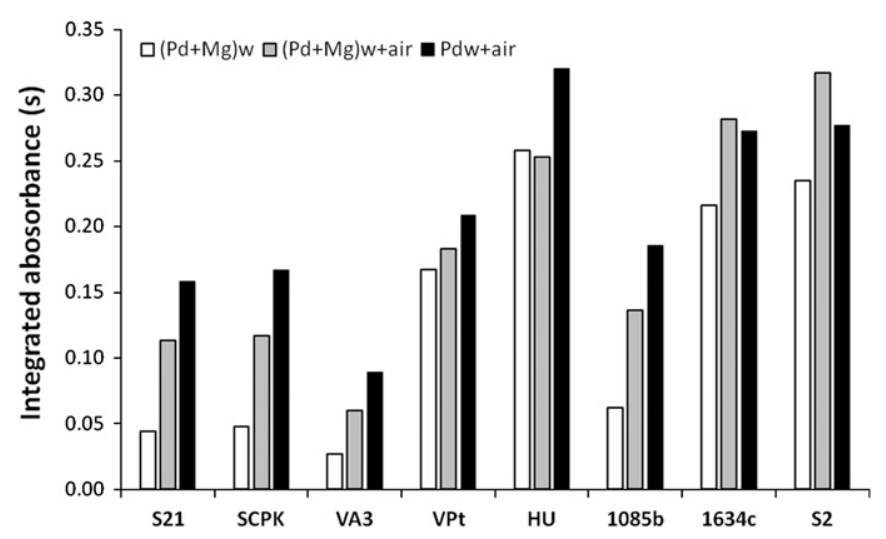

Fig. 5. Comparison of $\mathrm{V}$ integrated absorbance in the experiments without and with air ashing.

modifier solution is favorable here (Fig. $4 \mathrm{~b}$ and $4 \mathrm{c}$ ). It is interesting that in the case of $(\mathrm{Pd}+\mathrm{Mg})_{\mathrm{w}}$ and $(\mathrm{Pd}+\mathrm{Mg})_{\mathrm{dl}}$ the order of the modifier and the sample application is the same, but in the second case the sample solution is dried and thermally pretreated before the modifier injection. This can obviously decrease the contact and the interaction of $\mathrm{V}$ and $\mathrm{Mg}$, resulting in more efficient atomization in the case of S21, SCPK and VA3. However, it also decreases the contact and the interaction of $\mathrm{V}$ and $\mathrm{Pd}$, resulting in an increase in volatility losses in the case of VPt, $1634 \mathrm{c}$ and S2 (Fig. 4b).

\subsection{Experiments with air ashing and $I_{2}+M T O A C l$ pretreatment}

Apart from Pd, the application of air in the pyrolysis stage turned out to be crucial for the determination of $\mathrm{Ni} \mathrm{[48]} \mathrm{and} \mathrm{V}$ porphyrins [35] and in the determination of $\mathrm{V}$ in residues and heavy fractions from petroleum distillation [35]. In some other analyses, for example in the determination of $\mathrm{Pb}$ in the form of $\mathrm{Pb}$ cyclohexanebutyrate [46] or the determination of $\mathrm{V}$ or $\mathrm{Ni}$ in forms containing O-bound metal (e.g. S21, VC, VA3 and VA4) [35,52], the

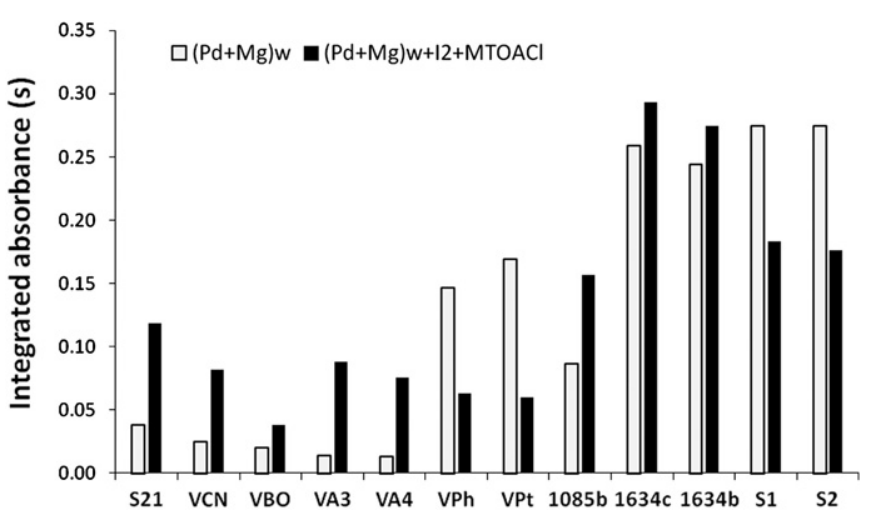

Fig. 6. Comparison of $\mathrm{V}$ integrated absorbance in experiments without and with $\mathrm{I}_{2}+\mathrm{MTOACl}$ pretreatment.

pretreatment with iodine dissolved in toluene, followed by a treatment with $\mathrm{MTOACl}$ was indispensable.

We therefore investigated how air ashing and pretreatment with $\mathrm{I}_{2}+\mathrm{MTOACl}$ could influence the determination of $\mathrm{V}$ using the $(\mathrm{Pd}+\mathrm{Mg})_{\mathrm{w}}$ modifier (Figs. 5 and 6). The air ashing improved the integrated absorbance of most of the $\mathrm{V}$ forms, while the $\mathrm{I}_{2}+$ MTOACl pretreatment increased only the integrated absorbance of S21, SCPK, 1085b and 1634c and the compounds having O-bound V (VBO, VA3 and VA4). At the same time the $\mathrm{I}_{2}+\mathrm{MTOACl}$ pretreatment decreased the integrated absorbance of porphyrins and the fractions from distillation. The joint application of the air ashing and $(\mathrm{Pd}+\mathrm{Mg})_{\mathrm{w}}$ modifier is less effective than the air ashing applied with $\mathrm{Pd}_{\mathrm{w}}$; the interesting exception is the heavy fraction from distillation (S2).

It should be added that atomic absorption peak of $\mathrm{V}$ using $(\mathrm{Pd}+\mathrm{Mg})_{\mathrm{w}}+$ air ashing appeared on average $0.1 \mathrm{~s}$ earlier than the peak using only $(\mathrm{Pd}+\mathrm{Mg})_{\mathrm{w}}$. The peak shift and the increase of the integrated absorbance of $\mathrm{V}$ after air ashing is a confirmation of the assumption of refractory carbide formation. In the case of $\mathrm{V}$ atomization from vanadium oxide the opposite effect of oxygen should be expected [45]. 


\subsection{Experiments using HR-CS AAS with transversal heating of graphite furnace}

The application of equipment of different optical and heating system enables to evaluate the probability of interferences and to determine the causes for the decrease of atomic absorption signals. Therefore, some of the results discussed above and obtained using longitudinally heated medium-resolution line source systems have been repeated using a transversely heated high-resolution continuum source system (contrAA 700).

For S21, SCPK, VA3 and 1085b the integrated absorbance with the $(\mathrm{Pd}+\mathrm{Mg})_{\mathrm{w}}$ modifier was decreased to $32,34,30$ and $38 \%$ of the value obtained for $\mathrm{Pd}_{\mathrm{w}}$. The decrease for VPt and $\mathrm{HU}$ was $67 \%$ and $87 \%$, respectively. For $1634 \mathrm{c}$ and S2 the integrated absorbance has changed less than 10\%. Thus, the effect of addition of MgA to PdA is similar as shown for the solar spectrometers in the Fig. 1b. The application of more isothermal atomization condition, because of transverse heating, does not help to overcome the decrease as it is not caused by gas-phase interferences. Also better resolution and background correction possibilities do not reveal any spectral effects as the cause of the V signal decrease [19,51].

\subsection{General discussion}

It could be anticipated that $\mathrm{MgA}$, soluble in xylene, could replace $\operatorname{Mg}\left(\mathrm{NO}_{3}\right)_{2}$, insoluble in the solvent, for organic solutions analysis. Unfortunately, instead of thermal stabilization and unification of behavior of various $V$ forms, a significant decrease of signal was observed. The effect strongly depends on the chemical form of $\mathrm{V}$, which can lead to erroneous results. In all comparative experiments (e.g. Figs. 1, 4-6) it appears that the effects of $\mathrm{Mg}$ application are similar for similar $\mathrm{V}$ compounds/ samples. Therefore, after careful standards selection it is possible to use GF AAS for direct analysis in an organic solution and to take all advantages of such an analysis (high sensitivity, low detection limits, speed and automation).

The comparative experiments do not only show similarities and differences in single V-compounds behavior, but also in CRM-petroleum products behavior. For example, the $1085 \mathrm{~b}$ lubricating oil behaves differently than "dark" products from distillation, 1634b and S2 (Figs. 1-6). It can even behave differently than HU lubricating oil (Figs. 1a, 4c, 5). In the light of this finding, it is very important not to take an improper petroleum product for verification of analysis accuracy. This work shows that some technical details can significantly influence the integrated absorbance of an analyte in GF AAS, e.g. the separate or the joint injection of the modifier solution and the analyte solution $(4 a-4 c)$, the order of the injection of the modifier solution and the analyte solution (Fig. 4b) and the presence of components of a mixed modifier in one or in a few solutions (Fig. 4d). It can be crucial to have information on the details when results of various works are compared.

The influence of $\mathrm{Mg}$ on the $\mathrm{V}$ determination can be a source of inaccuracy in the $\mathrm{V}$ determination in petroleum products originally containing $\mathrm{Mg}$. In the case of analysis of unknown kind of sample it is recommended to check $\mathrm{Mg}$ presence/influence in recovery test of $\mathrm{V}$ added to the sample in the form being influenced by MgA.

A reasonable explanation for the decrease of the $V$ signal appears to be a more pronounced formation of refractory $\mathrm{V}$ compounds, stimulated by MgA. The formation of mixed compounds, such as magnesium-vanadium carbides that are more refractory than single carbides could be assumed; however, Mg forms salt-like carbides and $\mathrm{V}$ forms interstitial carbides, which is contrast to $\mathrm{W}, \mathrm{Zr}$, Ta and $\mathrm{Nb}$, investigated in Ref. [45].
Although large-scale technical processes might follow different mechanisms, it might be worth mentioning that application of $\mathrm{Mg}$ powder was reported for the synthesis of $\mathrm{V}_{2} \mathrm{C}$ [53] or VC [54] carbides. $\mathrm{V}_{2} \mathrm{O}_{5}$ was the substrate in both cases and $\mathrm{CaC}_{2}$ [53] or citric acid (potassium acetate) [54] were the source of C. Preparation of $\mathrm{C}$ of high structural order was also reported with participation of $\mathrm{Mg}$ by decomposition of magnesium carbides between 950 and $1200{ }^{\circ} \mathrm{C}$ [55]. The source of $\mathrm{C}$ was $\mathrm{CaC}_{2}$ which reacted with $\mathrm{MgCl}_{2}$. Crystalline $\mathrm{C}$ was formed by conversion of $\mathrm{MgC}_{2}$ to $\mathrm{Mg}_{2} \mathrm{C}_{3}$ and subsequent decomposition of the latter to $\mathrm{C}$ and $\mathrm{Mg}$, which, formed in situ, appeared to catalyze rearrangement of $C$ atoms to a higher degree of order [55].

This work is mainly practically oriented and does not pretend to give full explanation of the atomization mechanism of $\mathrm{V}$, which would need more sophisticated experimental tools [14,41]. It is certain from experiments done in this work that MgA stimulates the formation of refractory $\mathrm{V}$ compounds (Fig. 3). Probably V forms various carbides or different carbides in the absence and presence of MgA. The relatively little or negligible effect of MgA in the case of "dark" petroleum products could be the result of the "protective" action of asphaltenes, which cause easier V atomization than in the case of samples/V forms sensitive to MgA effect.

\section{Conclusions}

MgA can significantly decrease signal of organic $V$ form in GF AAS. The effect depends on the $\mathrm{V}$ compound, the analysis conditions and some technical details, e.g. separate or joint injection of the modifier solution and the analyte solution, the order of the injection of the modifier solution and the analyte solution as well as the presence of components of a mixed modifier in one or in a few solutions. There were not any differences in the behavior of $\mathrm{V}$ at various oxidation state stated (VA3 and VA4).

In comparative experiments using transversely heated HR-CS AAS and longitudinally heated LS AAS it was confirmed that neither spectral nor gas-phase interferences were causing the MgA effect on the integrated absorbance of $\mathrm{V}$. The stronger formation of refractory $\mathrm{V}$ carbides stimulated by $\mathrm{MgA}$ and the importance of the interactions with graphite would be anticipated as the cause of $\mathrm{V}$ integrated absorbance decrease by MgA. The conclusion bases on the delayed and decreased atomic absorption of $\mathrm{V}$ in the presence of MgA, the positive effect of air ashing, the $\mathrm{V}$ peak tailing and the influence of the way of modifier application.

Generally, the application of Mg acetylacetonate for determination of $\mathrm{V}$ in xylene solution is not recommended. The conclusion concerns application of MgA as a single modifier and mixed MgA with PdA modifier. In the case of analysis of an unknown sample of petroleum or products of its distillation (distillates, residue) the joint application of Pd modifier $\left(\mathrm{Pd}_{\mathrm{w}}\right)$ and air ashing should be further [35] the best option of chemical modifier. In the case of completely unknown organic sample the joint application of Pd modifier $\left(\mathrm{P}_{\mathrm{dw}}\right)$, air ashing and pretreatment with $\mathrm{I}_{2}+\mathrm{MTOACl}$ would be recommended. However, the $\mathrm{Mg}$ presence/influence should be checked in recovery test of $\mathrm{V}$ added to the sample in the form being influenced by $\mathrm{MgA}$. Mg can make impossible $\mathrm{V}$ determination.

Apart from complexity of processes taking place during GF AAS analysis in an organic solution, these determinations can be successfully done if similarity of behavior of similar analyte compounds (samples) is a base of calibration. Very important finding of this work is that various petroleum products can behave differently during analysis, therefore CRMs should be carefully selected, e.g. lubricating oil can be improper CRM for analysis of fuel oil. 


\section{Acknowledgment}

The authors warmly thank Teresa Terebus for technical assistance and all help.

This work was partially supported by the Polish Ministry of Science in the frame of statutory funds for Research-Development Center for Refinery Industry S.A.

The authors are also grateful to Conselho Nacional de Desenvolvimento Científico e Tecnológico (CNPq) and Coordenação de Aperfeiçoamento de Pessoal de Nível Superior (CAPES) for research scholarships and financial support.

\section{References}

[1] T.T. Gorsuch, Analyst 84 (1959) 135-173.

[2] W. Slavin, G.R. Carnrick, D.C. Manning, Anal. Chem. 54 (1982) 621-624.

[3] U. Rohr, H.M. Ortner, G. Schlemmer, S. Weinbruch, B. Welz, Spectrochim. Acta Part B 54 (1999) 699-718.

[4] A.B. Volynsky, Spectrochim. Acta Part B 55 (2000) 103-150.

[5] D.L Tsalev, V.I. Slaveykova, in: J. Sneddon (Ed.), Advances in Atomic Spectroscopy, vol. 4, JAI, 1997, pp. 27-150.

[6] D.L. Styris, D.A. Redfield, Anal. Chem. 59 (1987) 2897-2903.

[7] D.L. Styris, D.A. Redfield, Anal. Chem. 59 (1987) 2891-2897.

[8] V. Majidi, N. Xu, R.G. Smith, Spectrochim. Acta Part B 55 (2000) 3-35.

[9] V. Majidi, R.G. Smith, N. Xu, M.W McMahon, R. Bossio, Spectrochim. Acta Part B 55 (2000) 1787-1822.

[10] L.J. Prell, D.L. Styris, D.A. Redfield, J. Anal. At. Spectrom. 6 (1991) 25-32.

[11] D.A. Katskov, G. Daminelli, P. Tittarelli, Spectrochim. Acta Par B 54 (1999) 1045-1062.

[12] D.A. Katskov, P. Tittarelli, Spectrochim. Acta Part B 55 (2000) 375-377.

[13] G. Daminelli, D.A. Katskov, R.M. Mofolo, T. Kantor, Spectrochim. Acta Part B 54 (1999) 683-697.

[14] H. Ortner, E. Bulska, U. Rohr, G. Schlemmer, S. Weinbruch, B. Welz, Spectrochim. Acta Part B 57 (2002) 1835-1853.

[15] U..Rohr, Korrosionsphanomene und Wirkungsmechanismen in der GraphitorAtomoabsorptionspectrometrie, Ph.D. Thesis, Darmstadt University of Technology, 1996.

[16] G. Schlemmer, B. Welz, Spectrochim. Acta Part B 41 (1986) 1157-1165.

[17] B. Welz, G. Schlemmer, J.R. Mudakavi, J. Anal. At. Spectrom. 7 (1992) 1257-1271.

[18] H. Qiao, K.W. Jackson, Spectrochim. Acta Part B 46 (1991) 1841-1859.

[19] S. Xiao-Quan, W. Bei, J. Anal. At. Spectrom. 10 (1995) 791-798.

[20] M.M. Barbooti, F. Jasim, Talanta 29 (1982) 107-111.

[21] M.C. Gonzalez, A.R. Rodriquez, V. Gonzalez, Microchem. J. 35 (1987) 94.

[22] P. Bermejo Barrera, C.P. Calvo, F.Bermejo Martinez, Anal. Lett. 24 (1991) 447-458.

[23] N.N. Meeravali, S.J. Kumar, J. Anal. At. Spectrom. 16 (2001) 527-532.
[24] R.Q. Aucelio, A. Doyle, B.S. Pizzorno, M.L.B. Tristao, R.C. Campos, Microchem J. 78 (2004) 21-26.

[25] D.S.S. dos Santos, A.P. Teixeira, M.G.A. Korn, L.S.G. Teixeira, Spectrochim. Acta Part B 61 (2006) 592.

[26] C.F. Damin, M.G.R. Vale, M.M. Silva, B. Welz, F.G. Lepri, W.N.L. dos Santos, S.L.C. Ferreira, J. Anal. At. Spectrom. 20 (2005) 1332-1336.

[27] F.G. Lepri, B. Welz, D.L.G. Borges, A.F Silva, M.G.R Vale, U. Heitmann, Anal. Chim. Acta 558 (2006) 195-200.

[28] R.E. Santelli, M.A. Bezzerra, A.S. Freire, E.P. Oliveira, M.F.B. Carvallo, Fuel 87 (2007) 1622-1671.

[29] M.G.R. Vale, M.S. Silva, I.C.F. Damin, P.J.S. Filho, B. Welz, Talanta 74 (2008) 1385-1391.

[30] M.M. Silva, I.C.F. Damin, M.G.R. Vale, B. Welz, Talanta 71 (2007) 1877-1885.

[31] G.P. Brandao, R.C. Campos, E.V.R. Catro, H.C. Jesus, Spectrochim. Acta Part B 62 (2007) 962-969.

[32] D.P.C. Quadros, E.S. Chaves, F.G. Lepri, D.L.G. Borges, B. Welz, H. Becker-Ross, A.J. Curtius, Energy Fuels 24 (2010) 5907-5911.

[33] Y. Nakamoto, T. Ishimaru, N. Endo, K. Matsusaki, Anal. Sci. 20 (2004) 739-741.

[34] N.S. Thomaidis, E.A. Piperaki, Analyst 121 (1996) 111-117.

[35] Z. Kowalewska, Spectrochim. Acta Part B 62 (2007) 273-282.

[36 ] F.A.C. Amorim, B. Welz, A.C.S. Costa, F.G. Lepri, M.G.R. Vale, S.L.C. Ferreira, Talanta 72 (2007) 349-359.

[37] W. Wendl, G. Müller-Vogt, Spectrochim. Acta Part B 39 (1984) 237-242.

[38] W. Wendl, G. Müller-Vogt, Spectrochim. Acta Part B 40 (1985) 527-531.

[39] R.E. Sturgeon, C.L. Chakrabarti, C.H. Langford, Anal. Chem. 48 (1976) 1792-1807.

[40] D.L. Styris, J.H. Kaye, Anal. Chem. 54 (1982) 864-869.

[41] B. Welz, M. Sperling, Atomic Absorption Spectrometry, Wiley-VCH Verlag, Weinheim, 1999.

[42] J.A. Holcombe, Spectrochim. Acta Part B 44 (1989) 975-983.

[43] P. Pandano, J. Sneddon, Appl. Spectrosc. 43 (1989) 504.

[44] D.C. Manning, W. Slavin, Spectrochim. Acta Part B 40 (1985) 462-473.

[45] A. Hulanicki, R. Karwowska, J. Stanczak, Talanta 27 (1980) 214-216.

[46] Z. Kowalewska, E. Bulska, A. Hulanicki, Spectrochim. Acta Part B 54 (1999) 835-843.

[47] Z. Kowalewska, Spectrochim. Acta Part B 66 (2011) 546-556.

[48] W.R. Antipienko, W.N. Miełkow, W.I. Titow, Nieftekhimija XIX (1979) 723-737.

[49] P. Vahaoja, I. Valimaki, K. Roppola, T. Kuoakken, S. Lahdelma, Crit. Rev. Anal. Chem. 38 (2008) 67-83.

[50] K.B. Peyton, Fuel Field Manual. Sources and Solutions to Performance Problems, Nalco/Exxon Energy Chemicals, L.P, McGraw-Hill, New York, 1997.

[51] B. Welz, H. Becker-Ross, S. Florek, U. Heitmann, High-Resolution Continuum Source AAS, Wiley-VCH, Weinheim, 2005.

[52] Z. Kowalewska, Spectrochim. Acta Part B 67 (2012) 31-39.

[53] L. Wang, Q. Li, Y. Zhu, Y. Qian, Int. J. Refract. Met. Hard Mater. 31 (2012) 288-292.

[54] Y. Chen, H. Zhang, H. Ye, J. Ma, Int. J. Refract. Met. Hard Mater. 29 (2011) 528-531.

[55] D. Osetzky, Carbon 12 (1974) 517-523. 